\author{
Angela Pollak \\ University of Western Ontario, London, Ontario, Canada
}

Dr. Julia Hersberger

University of North Carolina at Greensboro, Greensboro, NC, United States

Shelbi Webb

University of North Carolina at Greensboro, Greensboro, NC, United States

\title{
THE ROLE OF HUMAN INFORMATION BEHAVIOUR IN RESILIENCE AND RECOVERY
}

\begin{abstract}
:
Theoretical conceptualisations of resilience and recovery are examined in this paper to determine how critical elements of information behaviour interact while individuals attempt to regain equilibrium following a crisis event. Situated within the larger historical, social, scientific and psychological landscape, this review of the literature suggests that individuals who actively engage in positive information behaviour are generally perceived as better able to acquire needed resources to aid in recovery efforts post-trauma in order to achieve equilibrium or even improve on their previous status to achieve a level above that (thriving). Individuals who experience information difficulties find recovering or thriving more difficult and may be perceived as less resilient.
\end{abstract}

\section{Introduction}

Resiliency is a particularly timely topic as a global pandemic has resulted in the need for everyone to change behaviours, and invoke information seeking behaviours in particular, to cope with imposed and recommended changes. Over the course of many years trying to better understand the information behaviours and practices of populations considered 'at-risk' economically, emotionally, socially, physically, geographically - the stories that stand out as most remarkable are often those belonging to the outliers - the people who somehow managed, despite extreme vulnerabilities and all odds, to survive the unthinkable for long periods, and to sometimes even rescue themselves from their circumstances (Hersberger, 2003, 2013; Pollak, 2015, 2016). Often we describe people like this as resilient. As this presentation illustrates, the term is actually much more complex than our colloquial understanding suggests. While many important insights have been gained by inter- and trans-disciplinary academic inquiry, an equal or greater number of ambiguities about the concept persist making the idea of resilience extremely difficult to operationalize regardless of discipline. While information studies research has touched on the concept periodically and in limited ways, the time is right for a fuller examination of how resilience fits into our understanding of information behaviours and practices. The purpose of this presentation therefore is to present a history of resilience research, to merge together critical concepts from different disciplines that inform an analytical framework of resiliency, and then to delineate the information behaviours and practices within these 
concepts to better understand specific characteristics of what might be considered information resilience. It is intended as a bridge to connect shared ideas across disciplines. These concepts, plus examination of the larger social context of resilience including arguments highlighting conceptual challenge areas, will be explored and critiqued more fully in two upcoming papers currently in preparation for submission to CJILS.

\section{What is Resilience?}

In general, the seeds for examining resilience appear in widespread observations of occasions when people and systems "function remarkably better than objective circumstances suggest they should" (Norris et al. 2009, 2190). Several paradigmatic approaches have been identified from which to examine this phenomenon. Based on research into the sustainability of natural ecosystems involving plants, animals, and insects, Canadian ecologist C. S. Holling noted the historical tendency of researchers in his field to examine the ability of a system to return to an equilibrium state after disruption within ideal and controlled circumstances, which he referred to as the stability paradigm. Since Holling's own observations highlighted that in practice such control was seldom achievable, he favoured a flexibility paradigm which he defined as "the capacity of a system to experience shocks while retaining essentially the same function, structure, feedbacks, and therefore identity" (Walker et. al. 2006, 2). A key feature of both the stability and flexibility paradigms was that they were descriptive, meaning that associated variables could be isolated and measured quantitatively and precisely (Brand \& Jax 2007). Brand and Jax, however, noted that vague definitions of resilience in other disciplines were still very useful tools because they cast resilience as a boundary object (a term coined by Star and Griesemer 1989) in institutional ecology studies, which opened opportunity for qualitative inquiry. Around the same time, a further shift in thinking about resilience moved investigation away from problem-based or pathogenic approaches in favour of positivist and fortegenic approaches to research which examined strengths instead of weakness (Van Breda 2001). Examples of most of these paradigms can be found in LIS research that touches on the concept of information resilience.

\section{Mapping the Resilience Process to ISU Research}

Our literature review highlights four stages in the resilience process - baseline, trigger, response and outcome. Although not described as such in LIS traditions, all four stages map quite nicely to literature on information seeking and use (ISU) and trauma.

\section{Information Baseline}

Baseline refers to the normal state or store of information seeking beliefs and practices a person possesses and uses in their daily life, including the cumulative repository of information literacy skills learned through informal, personal, familial and social experiences, as well as training acquired through interaction with formal education systems across the lifespan that allow functioning in a state of balance. ISU understands the baseline to be context sensitive, and determined by many variables including the age and stage of the individual, experience, their literacy levels and prior exposure to literacy training, personal attitudes toward information seeking and problem solving in general, and their access to the necessary tools to engage in a search process. With a rich history of studying information seeking in situ, LIS researchers have examined a host of formal and informal baseline contexts too numerous to detail in full here (Boris 2005; Case 2007; Gabridge et al. 2008; R. 
Harris \& Wathen 2007; Hartel 2003; Isah, 2008; Leckie 1996, 2005; Lu 2010; Savolainen 1995; Shen 2013; Todd n.d.; Wilson 2009).

\section{Triggering Stressors}

Triggering stressors can arise in absolutely any sphere of life, professional or personal. They are often characterized in ISU literature as causing information gaps - some indication or recognition that there has been a change in information needs, usually an increased demand, that leaves the individual short of information that could be helpful in problem solving. It also includes an element of understanding or belief that acquiring information (additional, missing, more accurate information etc.) will in some way alleviate the stress caused by the change and return the individual to a state of equilibrium (Case 2016). Information behaviours related to both acute and chronic triggering stressors give insight into how information can both help and hinder recovery. For example, discovering how information is used formally and informally in the context of disaster information planning and management is a growing subdiscipline (Arnesen \& Chang 2019). Library service provision also has a strong history of exploring chronic stressors because they are commonly associated with a key demographic served by public libraries - disadvantaged and marginalized populations including the disabled, refugees and immigrants, and the homeless.

\section{Information Responses}

They ways people engage in different strategies to mitigate the effects of a negative experience, or how they cope with a triggering event constitutes the response phase. In ISU, the response stage translates to the way in which a person engages with information directly as a result of a change in their environmental demands or sensed need. Case highlights that motivations for seeking information may be objective, where an underlying "rational judgement" presupposes that certainty is possible and achievable through the acquisition of information (Case 2007). Subjective motivations are driven more by affective considerations and result in a less scripted process propelled by a vague sense of unease or anxiety or fear and a suspicion or curiosity about whether helpful information might be located. Thus, individual responses to a triggering event may range from exhibiting highly proactive, coordinated and advanced information seeking behaviours, to being unable or unwilling to act at all. Theories at play in information responses include reducing the uncertainty created by the triggering event (Belkin 1978; Kuhlthau 1991), or 'making sense' of the event in the context of their lives (Dervin 1983), monitoring, blunting and avoidance (Case et al. 2005, Case 2016, Golman et al. 2017) as well as other affective elements, which are an internal and subjectively realized experience (Wyer et al. 1999). In 2016, Fortier further categorized information responses into various profiles based on attitudes and beliefs toward information seeking.

\section{Outcomes}

Outcomes, of course, represent what happens after the information action or intervention. While much information seeking literature focuses on the assortment of 'successful' information seeking practices, or practices that allow a return to equilibrium, information seeking outcomes of course mirror the spectrum identified in the resilience literature. The act of seeking and using information returns the individual to the original equilibrium, or 
not, and in some cases, a new equilibrium may surpass the previous. For example, studies have explored outcomes associated with literacy interventions to determine efficacy in changing practices, or outcomes related to environments where poor information practices are known to exist (Chatman 1999; R. M. Harris \& Dewdney 1994) to find out why interventions may not be having the desired effect.

\section{Risk Factors and Protective Factors}

While information seeking and use research does not use the terms risk or protective factors, it does recognize that certain internal and external environmental factors influence outcomes. Information overload, or "a state in which too much information leads to a generalized state of anxiety and/or confusion" can negatively impact a person's ability to make decisions (Case 2016, 371 ) including leading to poor judgment, anxiety, and an inability to act (Blummer \& M. Kenton 2014, 116) while information literacy combats information overload leading to better outcomes (Lloyd 2015, 1029). Also noteworthy by their absence in the psychological literature reviewed for this article are the physical contributors to resilience we often talk about in ISU research, such as access to technology, or (digital) literacy that allows one to understand and use the available resources. ISU literature is much stronger in this area, with an extensive array of studies highlighting the benefits of technological literacy and the harms of the digital divide. Interventions related to self-initiated queries, imposed queries (Gross, 2000), or queries by proxy can influence outcomes. The concept of meaning making maps to Dervin's theory of sensemaking, which seeks to uncover details of the process of moving through an information cycle from identifying an information gap, to locating and using information, to the outcomes that follow. Lastly, the role of spirituality in information seeking is an interesting ISU subdiscipline as it deals with intangible information sources (Michels 2005, 2012). While not intended to advance our understanding of resilience specifically, their research extends our understanding of alternate reflective information seeking practices.

\section{Conclusion}

While information research has not yet devoted a lot of effort to studying resilience specifically, it is clear that there is synchronicity between resilience theory and existing information behaviour theory. Information science literature mirrors resilience research in that information resilience is not necessarily something one is born with, although circumstances of one's birth might necessarily be expected to influence capacity for resilience. Rather, information resilience is a skill that can be taught and learned over time. The record is scattered with intersection points highlighting how information behaviours and practices are built into the resilience process. Library service provision, for example, has a long-standing focus on delivering information literacy training particularly in formal education environments from elementary to postsecondary education levels. This fortigenic approach fosters resilient outcomes through proactive skill building over a long period of time, reinforcing one's ability to recognize a need, to confidently and effectively find and understand information that will fill the need, and then to decide whether or how to act on it.

Despite efforts to simplify the concept of resilience, it is important to understand that resilience is not a panacea. The concept is increasingly being challenged on a conceptual level, not to suggest that resilience doesn't exist, but rather to highlight the complex systems that give rise to episodes of resilience in the first place. For example, political, social, and economic factors 
creating the circumstances that drive the need for resilience are inherently tied to structural systems that organize, and in many instances oppress. These hegemonic, often colonial systems unfairly disadvantage minority populations, causing a greater need for resilience in certain populations to begin with. Focusing on individual characteristics of resilience as the main method to fight oppression should not obscure the need to fix the root problem through systemic changes. While we clearly need to understand more about resilience than we currently do, we must also be aware that resilience is not equally achievable by all, nor does it have the potential to fix all social ills.

One's place on the information resilience continuum varies by circumstance, by crisis and by each individual's ability to deal with the different demands of a crisis. This early attempt at mapping the intersection points is a call to other researchers to do the same, and to fully explore potential theories of information resilience.

\section{References}

Arnesen, S., \& Chang, F. (2019). Information and Readiness Build Resilience: The Role of the Disaster Information Management Research Center. Collaborative Librarianship, 11(1), 37-42. Library Literature \& Information Science Full Text (H.W. Wilson).

Belkin, N. J. (1978). Progress in documentation: Information concepts for information science. Journal of Documentation, 34(1), 55-85.

Blummer, B., \& M. Kenton, J. (2014). Reducing Patron Information Overload in Academic Libraries. College \& Undergraduate Libraries, 21(2), 115-135. Library Literature \& Information Science Full Text (H.W. Wilson).

Boris, L. (2005). The Digital Divide and its Impact on the Rural Community. Rural Libraries, 25(2), 7-35. 1lf.

Brand, F. S., \& Jax, K. (2007). Focusing the Meaning(s) of Resilience. Ecology and Society, 12(1). JSTOR. www.jstor.org/stable/26267855

Case, D. O., Andrews, J. E., \& Johnson, J. D. (2005). Avoiding versus seeking: the relationship of information seeking to avoidance, blunting, coping, dissonance, and related concepts. Journal of the Medical Library Association, 93(3), 353-362.

Case, D. O. (2007). Information Needs and Information Seeking. In Looking for information :a survey of research on information seeking, needs, and behavior (Vol. 2, pp. 68-83). Elsevier/Academic Press.

Case, D. O. (2016). Looking for information: A survey of research on information seeking, needs, and behavior (Fourth edition.). Emerald Group Publishing Limited.

Chatman, E. A. (1999). A theory of life in the round. Study of information poverty in a women's maximum-security prison. Journal of the American Society for Information Science, 50(3), 207-217. 
Dervin, B. (1983). An overview of sense-making research: Concepts, methods and results. Paper Presented at the Annual Meeting of the International Communication Association, Dallas, TX, Dallas, TX. [On-line]. Available: http:/faculty.washington.edu/wpratt/MEBI598/Methods/An\%20Overview\%20of\%20Sen se-Making\%20Research\%201983a.htm

Gabridge, T., Gaskell, M., \& Stout, A. (2008). Information seeking through students' eyes: The MIT photo diary study. College \& Research Libraries, 69(6), 510-522.

Golman, R., Hagmann, D., \& Loewenstein, G. (2017). Information Avoidance. Journal of Economic Literature, 55(1), 96-135. http://www.jstor.org/stable/26303232

Gross, M. (2000). The imposed query and information services for children. Journal of Youth Services in Libraries, 13(2), 10-17. Library Literature \& Information Science Full Text (H.W. Wilson).

Harris, R. M., \& Dewdney, P. (1994). Barriers to information: How formal help systems fail battered women (Vol. 81). Greenwood Press.

Harris, R., \& Wathen, N. (2007). "If My Mother Was Alive I'd Probably Have Called Her": Women's Search for Health Information in Rural Canada. Reference \& User Services Quarterly, 47(1), 67-79. 1lf.

Hartel, J. K. (2003). The serious leisure frontier in library and information science: Hobby domains. Knowledge Organization, 30(3/4), 228-238.

Hersberger, J. (2003). Are the economically poor information poor? Does the digital divide affect the homeless and access to information? Canadian Journal of Information and Library Science, 27(3), 45-63.

Hersberger, J. (2013). Resilience theory, information behaviour, and social support in everyday life. Proceedings of the Annual Conference of CAIS / Actes Du Congrès Annuel de l'ACSI, 0. http://www.cais-acsi.ca/ojs/index.php/cais/article/view/273

Holling, C. S. (1973). Resilience and Stability of Ecological Systems. Annual Review of Ecology and Systematics, 4, 1-23. JSTOR. https://www.jstor.org/stable/2096802

Isah, E. E. (2008). The information practices of physicians in clinical practice. Information Research, 13(4), 41-41. http://www.informationr.net/ir/13-4/wks02.html

Kuhlthau, C. C. (1991). Inside the Search Process: Information Seeking from the User's Perspective. Journal of the American Society for Information Science (1986-1998), 42(5), 361.

Leckie, G. J. (1996). Female farmers and the social construction of access to agricultural information. Survey in southwestern Ontario. Library \& Information Science Research, 18(4), 297-321.

Leckie, G. J. (2005). General model of the information seeking of professionals. In K. E. Fisher, S. Erdelez, \& L. E. F. McKechnie (Eds.), Theories of Information Behavior (Vol. 1- 
Book, Section, p. 158). Published for the American Society for Information Science and Technology by Information Today.

Lloyd, A. (2015). Stranger in a strange land: Enabling information resilience in resettlement landscapes. Journal of Documentation, 71(5), 1029-1042. 1lf.

Lu, Y.-L. (2010). Children's information seeking in coping with daily-life problems: An investigation of fifth- and sixth-grade students. Library \& Information Science Research (07408188), 32(1), 77-88. https://doi.org/10.1016/j.lisr.2009.09.004

Michels, D. H. (2005). The Use of People as Information Sources in Biblical Studies Research. Canadian Journal of Information \& Library Sciences, 29(1), 91-109.

Michels, D. H. (2012). Seeking God's Will: The Experience of Information Seeking by Leaders of a Church in Transition. Canadian Journal of Information \& Library Sciences, 36(1), 16-27. https://doi.org/10.1353/ils.2012.0003

Norris, F. H., Tracy, M., \& Galea, S. (2009). Looking for resilience: Understanding the longitudinal trajectories of responses to stress. Social Science \& Medicine, 68(12), 21902198. https://doi.org/10.1016/j.socscimed.2009.03.043

Pollak, A. (2015). Words to live by: How experience shapes our information world at work, play and in everyday life. University of Western Ontario. http://ir.lib.uwo.ca/etd/2722

Pollak, A. (2016). Information seeking and use in the context of minimalist lifestyles. Journal of Documentation, 72(6), 1228-1250. https://doi.org/10.1108/JD-03-2016-0035

Savolainen, R. (1995). Everyday life information seeking: Approaching information seeking in the context of "way of life." Library \& Information Science Research, 17(Journal Article), 259-294.

Shen, L. (2013). Out of Information Poverty: Library Services for Urban Marginalized Immigrants. Urban Library Journal, 19(1), 1-12. 1lf.

Star, S. L., \& Griesemer, J. R. (1989). Institutional Ecology, ‘Translations’ and Boundary Objects: Amateurs and Professionals in Berkeley's Museum of Vertebrate Zoology, 1907-39. Social Studies of Science, 19(3), 387-420. https://doi.org/10.1177/030631289019003001

Todd, R. J. (n.d.). Adolescents of the Information Age: Patterns of Information Seeking and Use, and Implications for Information Professionals. School Libraries Worldwide, 9(2), 27-46.

Van Breda, A. D. (2001). Resilience theory: A literature Review. South African Military Health Service, Military Psychological Institute, Social Work Research \& Development, 54.

Walker, B., L. Gunderson, A. Kinzig, C. Folke, S. Carpenter, and L. Schultz. (2006). A handful of heuristics and some propositions for understanding resilience in social-ecological systems. Ecology and Society 11(1):13. http://www.ecolog yandsociety.org/vol11/iss 1/art13/. 
Wilson, V. (2009). Boys are Reading, but their Choices are not Valued by Teachers and Librarians. Evidence Based Library and Information Practice, 4(3), 46-48.

Wyer, R. S., Clore, G. L., \& Isbell, L. M. (1999). Affect and Information Processing (Vol. 31, p. 77). Elsevier Science \& Technology. https://doi.org/10.1016/S0065-2601(08)60271-3 